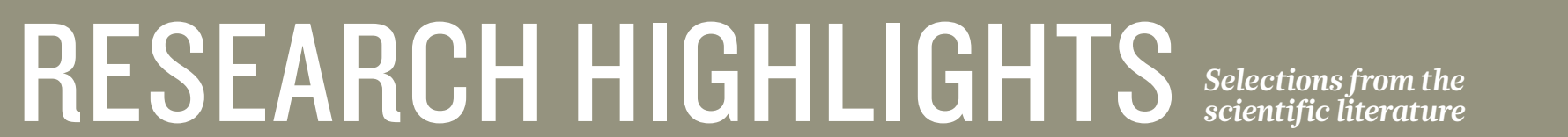

PHYSIOLOGY

\section{How alcohol ramps up hunger signals}

Brain cells that regulate appetite and feeding are activated by alcohol, offering a possible explanation for why drinking can lead to overeating.

Sarah Cains at the Francis Crick Institute in London and her colleagues exposed mice to alcohol for three days and found that the animals' food intake increased during that period. An analysis of mouse brain tissue showed that alcohol boosts the activity of Agrp neurons, which trigger feelings of intense hunger when stimulated. The activity level was similar to that caused by fasting or hunger hormones.

When the team silenced these cells in mice and then gave them alcohol, the animals did not increase their eating.

Nature Commun. 8, 14014 (2017)

\section{ECOLOGY}

\section{Invasive wild pigs spread across US}

Eurasian wild pigs transmit disease and destroy crops in the United States, and are expected to spread throughout the country in the coming decades.

The invasive wild pigs (Sus scrofa; pictured) compete with

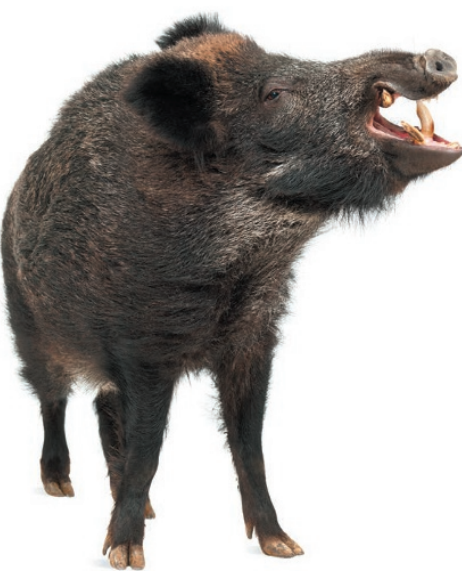

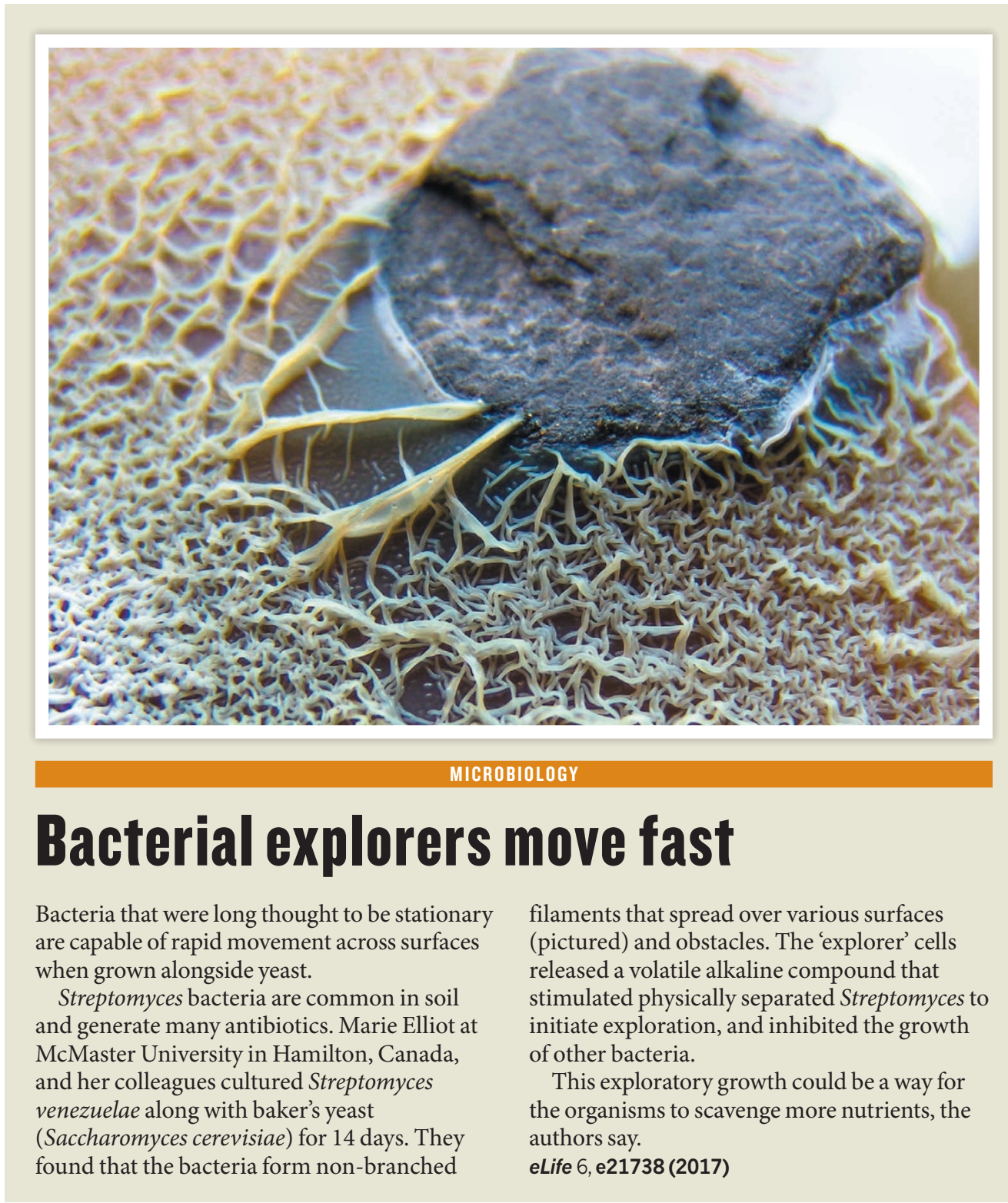

the country's native wildlife and cost the agricultural industry more than US $\$ 1.5$ billion a year. To predict their future spread, Nathan Snow, now at the USDA National Wildlife Research Center in Fort Collins, Colorado, and his colleagues modelled the distribution of wild pigs in the continental United States from 1982 to 2012. The authors found that, during this period, the pigs' rate of northward range expansion accelerated from 6.5 kilometres to 12.6 kilometres per year. If this trend persists, wild pigs are predicted to reach most counties in 30-50 years.

A warming climate may aid the northerly spread of the animals, the authors say, adding that reducing the transport of wild pigs - both accidentally and for sport will be important in limiting the invasion.

J. Appl. Ecol. http://doi.org/bwsp (2016)

\section{NEUROSCIENCE \\ Age sees boost in facial recognition}

The brain is thought to trim back neural connections as it develops, but scientists report that the region we rely on to recognize faces continues to increase in size into adulthood.

Kalanit Grill-Spector at Stanford University in California and her 